\title{
Contribuições do campo crítico do lazer para a promoção da saúde
}

\section{Contributions from the critical leisure field to the health promotion}

M iguel Sidenei Bacheladenski ${ }^{1}$

Edgard $M$ atiello Júnior ${ }^{2}$

${ }^{1}$ Pró-Reitoria de Extensão e Cultura, UNICENTRO. Rua Salvatore Renna- Padre Salvador 875, Santa Cruz. 85015-430 Guarapuava PR miguelsb@brturbo.com.br ${ }^{2}$ Departamento deEducação Física, Universidade Federal deSanta Catarina.
Abstract The studies about leisure for health promotion still tend to choose the active body occupation in the free-time (leisure activities), revealing the influence of the functionalist way of thinking, which trying to reduce the links between society and health-disease process, undoubtedly do not keep with the purpose of population health promotion. Focusing on this idea, and keeping in mind the premise that in the Brazilian physical training there are different opinions since the earliest $80 \mathrm{~s}$ which try to achieve the purpose to avoid the ideas of the functionalist way of thinking. However, those opinions are almost unknown both in the Brazilian public health system and the collective health system, once the bibliography revision about leisure activities development was made in the country, looking for ideas taken in common knowledge for health promotion presuppositions, this report has the aim to show critical and alternatives concepts of leisure in the way it is linked to healthy as a real social change, using a political-pedagogical proposal called lazerania. In general, this is an emancipatory concept of leisure, which comes from the sport phenomenon as a problem and provides the feeling, thinking and behavior of the population, trying to build a society based on solidarity and consumer participation.

Key words Leisure activities, Health promotion, Consumer participation, Social change
Resumo N os estudos do lazer para a promoção da saúde, ainda predomina a lógica da ocupação ativa do corpo no tempo de não-trabalho (lazer ativo), revelando a influência do pensamento funcionalista, o qual, ao reduzir os vínculos entre sociedade e processo saúde doença, indiscutivelmente não condiz com o propósito de promover a saúde da população. Em face destequadro, epartindo da premissa de quena educação física brasileira, desde o início dos anos oitenta, proliferam diferentes concepções que discutem a superação do discurso do lazer funcionalista, mas que tais formulações ainda são praticamente desconhecidas da Saúde Coletiva e Saúde Pública brasileiras, a partir de revisão bibliográfica sobre o desenvolvimento do campo do lazer no país, buscando reflexões conjunta aos pressupostos da promoção da saúde, este trabalho tem como objetivo apresentar concepções críticas ealternativas do lazer em sua relação com a saúde, fundamentando-senuma proposta político-pedagógica denominada lazerania. Em linhas gerais, esta éuma concepção de lazer emancipatório que, partindo da problematização do fenômeno esportivo, proporciona o sentir, pensar e agir da população, visando à construção de uma sociedade fundada na solidariedade e com a participação de todos.

Palavras-chave Atividades delazer, Promoção da saúde, Participação comunitária, Mudança social 
Introdução

O lazer tem sido reconhecido como um fenôme no de grande relevância para a emancipação humana e cidadania, figurando fortemente como estratégia da promoção da saúde. Apesar disto, nos campos da Saúde Coletiva e Saúde Pública, embora essas importâncias sejam frequentemente destacadas, é evidente como esse fenômeno é explorado de forma superficial, carecendo de reflexão crítica. Ainda predominam abordagensque o tratam como um direito eumanecessidadefundamental da humanidade que seexplica por si só, sem que sejam resgatadas as tensões históricas que envolvem sua concepção e sua conquista.

É isto o que nos indicaum levantamento junto à base de dados do SciELO (Scientific Electronic Library Online), realizado com o intuito de compreender como o lazer étratado nestes campos. Numa busca pelo assunto promoção de/da saúde, após serem localizados 95 estudos eidentificados quais mencionavam o lazer (inclusive como sinônimo de recreação/atividades recreativas), constatamos sua presença em 22 deles $(23,16 \%)$. N uma análise mais detal hada destes trabal hos, mediante técnicas de análise de conteúdo ${ }^{1}$, observamos que apenas Peres et al. ${ }^{2}$ discutiram estefenômeno, contudo, sem quetenham procedido a aprofundamentos e anunciado avanços teóricos e práticos para a área.

N os demais trabal hos, a menção ao lazer não foi além de sua mera inserção no texto, sendo ele ou simplesmente apontado como uma necessidade à saúde $\mathrm{e}^{3-9}$ e à qualidade de vida ${ }^{10,11}$, sem nenhuma discussão sobrea questão, ou, pior que isso, retratado como possibilidade para se vivenciar atividades que privilegiam aos conteúdos fí$\operatorname{sicos}^{12-23}$, revelando a influência dos pressupostos teóricos do funcionalismo.

Um pensamento que, ao desconsiderar os conflitos e contradições da sociedade, contribui com a manutenção do status quo, e, dessa forma, conformeentendimento deAwofeso ${ }^{24}$, não acompanha os fundamentos da promoção da saúde, afinal não possibilita o enfrentamento do crescente quadro de pobreza e exclusão social, reconhecidamente um dos agravantes da saúde pública mundial. Tendência esta também observada no campo da educação física (área que se dedica a estudar o lazer e que o tem como um dos principais conteúdos), no qual predominam as concepções de saúde com forte viés positivista e médico-higienista ${ }^{25,26}$. A associação do lazer com a promoção da saúde é restrita a uma forma de ocupação ativa do corpo no tempo do não-tra- balho (lazer ativo), tendo como decorrência a despolitização de ambos conceitos; a responsabilização dos sujeitos pelo alcance do lazer e da saúde e a perpetuação do paradoxo do lazer brasileiro: enquanto poucos podem desfrutar suas diferentes possibilidades, uma grandemaioria da população é obrigada, no máximo, a se contentar com um lazer precário e, por isso, na base do improviso.

Diante do exposto e considerando que na educação física brasileira proliferam desdeo início dos anos oitenta diferentes concepções que discutem a superação do discurso do lazer funcionalista, mas que tais formulações ainda são praticamente desconhecidas da Saúde Coletiva e Saúde Pública brasileiras, a partir de revisão bibliográfica sobre o desenvolvimento do campo do lazer no país, buscando reflexões conjunta aos pressupostos da promoção da saúde, este trabaIho tem como objetivo apresentar concepções críticas ealternativas do lazer em sua relação com a saúde, fundamentando-se numa proposta político-pedagógica denominada lazerania ${ }^{27}$.

\section{Sobrea promoção da saúde}

A concepção moderna de promoção da saúde perpassa a compreensão que se tem do processo saúde doença, revelando que o mesmo, além de não ser dicotômico em si, ainda extrapola os limites do campo estritamente sanitário. Incorporando um enfoque político e técnico em torno do processo saúde-doença, pode ser interpretada como uma reação à acentuada medicalização da vida social ecomo uma resposta setorial articuladora de recursos técnicos e posições ideológicas, substituindo a visão limitada da ausência de doença pela visão da erradicação de suas causas ${ }^{28}$.

A erradicação, entretanto, não está centrada no consumo de produtos, serviços eprocedimentos, mas marcada por um entendimento cognitivo, reflexivo e crítico que visa à instalação progressiva da saúde no lugar da doença. N este fim, a informação apresenta-se como uma importante estratégia, pois é só ela que permite entender e compartilhar as razões, as causas e consequências do adoecimento. Porém, isso não quer dizer que a promoção da saúde significa educar as pessoas como se elas fossem simples vasilhas a serem preenchidas pel o conhecimento científico. Trata-se de um processo que informa as pessoas através do diálogo com as mesmas, valorizando os saberes acumulados tanto pela ciência quanto pelas tradições culturais locai $s^{29}$. 
Por isso, Buss ${ }^{30}$ aponta o conhecimento popular ea participação social decorrentedestecomo a base de formulação do conceito promoção da saúde, que na Carta de Ottawa é expresso como "o processo de capacitação da comunidade para atuar na melhoria da sua qualidade de vida e saúde, incluindo uma maior participação no controle deste processo" ${ }^{31}$. Visando assegurar a igualdade deoportunidades eproporcionar osmeios para que as pessoas realizem completamente seu potencial desaúde, entende-se a promoção da saúde como um incremento do poder técnico eda consciência política das comunidades (empowerment) para apreensão de problemas e definição eimplementação de estratégias para a conquista de ambientes que favoreçam a saúde.

Podendo ser possibilitado pela ampla difusão de informações acerca das relações entre saúde e seus determinantes, o empowerment proporciona benefícios tanto no plano individual como organizacional (comunitário). Individualmente, as pessoas são estimuladas a desenvolver habilidades para agir em prol da melhoria de sua situação de vida, como, por exemplo, na luta por seus direitos de moradia. Por sua vez, quando organizados coletivamente, os indivíduos tomam posse de suas próprias vidas pela interação com seus pares, despertando o pensamento crítico em relação à real idade, o quefavorece a construção da capacidade social e pessoal, possibilitando a transformação das relações de poder ${ }^{32}$.

Assim, em linhas gerais, a promoção da saúde reforça o entendimento da saúde como um direito de todos e dever do Estado. Suas orientações defendem a redução das situaç̧ões que precarizam a vida social dos cidadãos e que, dessa forma, podem incidir negativamente no processo saúde doença. M as como as ações estatais têm sido historicamente insuficientes nesse propósito, cada vez mais a população é convocada para ser parceira, superando o sentido restrito de adotar os hábitos saudáveis, para participar ativamente de ações que possam romper com as estruturas políticas e econômicas, as grandes responsáveis pela concentração do poder na socie dade contemporânea.

Possibilidades e limites do lazer para a promoção da saúde

Partindo destas considerações, pode-sedizer que, na promoção da saúde, a participação da população não é apenas uma circunstância desejável, mas uma condição indispensável. A participação, no entanto, na concepção de $\mathrm{Demo}^{33}$, não pode ser entendida como dádiva, pois ela não é dada e sim conquistada. Também não seria uma concessão, já que não são os poderosos que cedem voluntariamente, mas a população que se impõe. E, por fim, também não é algo preexistente ou que caia do céu por descuido, mas uma resposta contra o processo histórico de dominação. Portanto, ao requerer "compromisso, envolvimento e presença em ações arriscadas eatétemerárias" ${ }^{33}$, a participação corresponde a um processo infindável eque, em conquista permanente, permiteà população se contrapor ao processo de dominação ao qual historicamente é imposta.

Sendo assim, acreditamos que a questão da participação possa perfeitamente orientar nossas reflexões sobre as possibilidades da educação física brasileira, especificamente através das atividades de lazer, contribuir nesta complexa tarefa. N esse sentido, analisando as concepções dos autores mais referenciados pelo campo do lazer no Brasil (Dumazedier ${ }^{34}$ e Marcellino ${ }^{35}$ ), bem como a proposta da pedagogia crítica do lazer ${ }^{27}$, nos atemos aos vínculos destas proposições com a sociedade.

\section{O desenvolvimento do campo do lazer no país e a tese do tempo livre}

As primeiras preocupações com o lazer no Brasil surgem no início do século $X X$, quando a transição da economia brasileira de agrário-exportadora para urbano-industrial vinha deteriorando acentuadamente as condições de vida dos trabaIhadores brasileiros. Sem a intenção de reduzir as injustiças sociais e, dessa forma, combater esse processo de deterioração, observa-se nos grandes centros 0 emprego de estratégias que servem apenas para amenizar seus efeitos. Uma destas foi a construção de equipamentos públicos de recreação, visando à manutenção da saúde da população e à recuperação da força de trabalho ${ }^{36}$.

No final dos anos sessenta, além de auxiliar na manutenção da saúde e recuperação da força de trabalho da população, sob influência européia e sendo tratado como um fenômeno social, o lazer épensando em sua capacidade de resolver questões políticas, tais como a adaptação do país às mudanças da produção capitalista de mercadorias. Indubitavelmente, uma exigência própria do mercado capitalista, já que da mesma forma que se expandia a produção de bens duráveis, era necessária uma interven ção estatal para se elevar na mesma proporção este consumo. 
Frigotto ${ }^{37}$ comenta que, nesta época, vigorava a tese de que, se uma nação subdesenvolvida investisse fortemente no capital humano, seu desenvolvimento obteria melhores resultados. Assim, como resposta à expansão da produção debens duráveis, o Estado tratou de oferecer saúde, educação e lazer aos brasileiros e, com isto, pretendia-se que a maior parte de seus salários fosse destinada ao consumo destes bens, o que poderia impulsionar a taxa de crescimento industrial que, em termos mundiais, já era uma das mais el evadas da época.

N esteprocesso, édese destacar a importância do Serviço Social do Comércio (SESC), pois foi por meio deste que, no início da década de setenta, o sociólogo francês joffre Dumazedier foi contratado para construção e desenvolvimento deum campo de conhecimento para o lazer no país. Quando chegou ao Brasil, Joffre Dumazedier tratou de difundir a concepção de lazer propugnada pelo seu envolvimento com o movimento operário francês, quando via, no tempo livre crescente, um espaço para a afirmação do direito dos operários ao lazer. Fruto de observações e enquetes sobre o lazer dos franceses, esta foi publicada em Vers une Civilisation du Loisir?, que, no Brasil, foi traduzida para Lazer e cultura popular ${ }^{34}$.

N esta, ao revelar a forma dos trabalhadores vivenciarem o lazer, além de sustentar suas reflexões sobre o lazer em oposição ao tempo de trabalho, Dumazedier também aponta que outras obrigações (familiares, sociais e religiosas) eram determinantes. Por isso, caracteriza o lazer como um conjunto de ocupações às quais o indivíduo pode entregar-se de livrevontade, seja para repousar, seja para desenvolver sua formação desinteressada, sua participação social voluntária, ou sua livre capacidade criadora, após livrar-se ou desembaraçar-se das obrigações profissionais, familiares e sociai $s^{34}$.

Uma concepção que reconheceo lazer com característica liberatória (libera o indivíduo de suas obrigações profissionais, familiares esociais); desinteressada (sem finalidade lucrativa, ideológica ou utilitária); pessoal (representa uma escolhapessoal) e hedonística (direcionada ao prazer, pois a satisfação é a condição primeira do lazer).

Com vistas à satisfação, as atividades de lazer são classificadas em cinco grupos de interesse: (1) manuais: atividades que podem ser desinteressadas e utilitárias ao mesmo tempo. Pela manipulação de objetos e produtos, podem constituir-se tanto num hobby como num trabalho não profissional; (2) físicas: neste grupo, os jogos predominam, pois a vida é jogada em detrimento de compromissos e, dessa forma, o lazer representa uma compensação; (3) artísticas: atividades que afastam o indivíduo da cultura vivida em direção da cultura mística, tal como cinema, teatro emuseus; (4) intelectuais: é a informação desinteressada apresentada como cultura permanente para acompanhar as rápidas transformações da sociedade (jornais, rádios, etc.); e (5) sociais: são atividades que favorecem a formação das coletividades e os relacionamentos interpessoais.

Embora discuta a satisfação das necessidades humanas, que a seu ver seriam o descanso (recuperação da fadiga advinda com o trabalho), a diversão (ruptura com o tédio da rotina diária) eo desenvolvimento (pessoal e social), em hipótese al guma, Dumazedier reflete sobre a dinâmica social que as geram. Elas seriam definidas da mesma forma para todas as pessoas, desconsiderando-se o fato da sociedade ser dividida por extratos sociais. Por isso, sua concepção aproxima-se dos pressupostos teóricos do funcionalismo, demonstrando a ideia denecessidades iguais para todos, passíveis de serem satisfeitas com atividades também iguais para todos ${ }^{38}$.

E é quando associado à saúde que este tratamento se torna mais evidente. Com uma abordagem compensatória às insatisfações da vida social, enquanto são valorizados seus conteúdos físicos e a consequente ocupação ativa do corpo, os determinantes gerais sobre as condições de saúde ( padrão adequado de nutrição, de habitação e de saneamento; boas condições de trabaIho; oportunidades deeducação ao longo de toda a vida; ambiente físico limpo, etc.), sequer são mencionados. Com um discurso simplório e bonito, apregoa-se que adoece somente quem quer, pois para ter uma melhor saúde, bastaria exercitar-sefisicamente.

Acompanhando o raciocínio de Barata ${ }^{39}$, entendemos que esta ideia, além de reduzir os vínculos entre sociedade e processo saúde-doença, ainda supervaloriza os esti los de vida e a promoção da saúde baseada na educação e responsabilização dos indivíduos por seu estado de saúdea chamada culpabilização da vítima. Como resultado, as pessoas que ocupam ativamente 0 corpo no lazer e se encontram sem doenças são congratuladas eincentivadas a continuarem com seu estilo de vida e, por sua vez, as pessoas doentes e sem a referida ocupação têm somente a si próprias a culpar.

Tudo porque esta ideia assenta-se na ilusão de que vivemos numa sociedade equilibrada efechada, sem conflitos ou contradições. 0 equilíbrio constitui-seno indicador da sociedadesaudá- 
vel ea influência externa, nestecaso, o sedentarismo, por sua suposta influência negativa, éo ponto a ser controlado. Afinal, como as contradições foram isoladas, acredita-seque, pelo controledos problemas, seria possível restabelecer o equilíbrio e, portanto, a salubridade da sociedade $e^{40}$.

Contudo, nesse contexto em que se dá única eexclusiva atenção às atividades dirigidas àtransformação dos comportamentos individuais, observa-se uma nítida contradição para com os preceitos da promoção da saúde. Ao invés de possibilitar a aquisição de consciência política (individual e comunitária) para se lutar em prol da conquista de melhores condições de vida à população, contribui com a permanência da vida socioeconômica em seu quadro atual. Para Demo ${ }^{33}$, isso se traduz em pobreza política e significa que as pessoas vivem na condição de massa de manobra, de objeto de dominação e manipulação, de instrumento a serviço dos outros.

E, nesta concepção de lazer, a pobreza política éretratada pela participação popular nas ações de promoção da atividade física e da promoção da saúde. Para retratá-la, ao considerarmos as características do compromisso, envolvimento e presença, tomamos como ponto de partida de reflexão a questão da presença. É evidentequeela existe, entretanto, si mplesmente resumida ao estar presente em atividades previamente organizadas, além, é claro, de respeitar os padrões de conduta estabelecidos para as mesmas. Com base em Santos ${ }^{41}$, as pessoas, ao invés de serem tratadas como cidadãos, aqui são vistas como meros consumidores de atividades e, nessa lógica, aceitam serem chamadas de usuários.

E o fato de assim aceitarem, pode-se dizer que se deve à forma com que elas se comprometem e envolvem nas atividades. Entendemos 0 envolvimento como dependente direto do compromisso, uma vez que este último refere-se à "decisão lúcida e profunda de quem o assume" 42 , ou seja, a capacidade de pensar eagir (conscientização). Em meio à forma com que as pessoas são incentivadas a praticar atividades físicas para a saúde, sendo responsabilizadas pela mesma, é fato que o compromisso por elas assumido éum compromisso para consigo mesmo (individual) e o envolvimento só vai até o ponto em que a pessoa entenda e veja ben efícios para si própria. Suas condutas reproduzem com exatidão a sociedade contemporânea, principalmente pelo individualismo que impera entre as pessoas.

Por isso, sem desmerecer as contribuições dessa concepção para o desenvolvimento do campo do lazer no país, compreendemos que seus fun- damentos são insuficientes para a complexa tarefa de promover saúde, pois ao invés de capacitar as pessoas para o enfrentamento de situações que afetam a vida da coletividade, contribui com a manutenção ou intensificação das mesmas.

A crítica ao tempo livre ea crença da transformação da sociedade

Embora não seja propriamente em sua relação com a saúde, desde o início dos anos oitenta, capitaneada pelas proposições de $\mathrm{N}$ elson Carval ho $\mathrm{M}$ arcellino ${ }^{35}$, observa-se uma forte contraposição à concepção de lazer de Joffre Dumazedier. Entenden do que ela vinha alimentando a alienação da população, como superação, o autor associa o lazer a dois conceitos - tempo e atitude. Deimediato, rompecom a noção do lazer restrito à ocupação do tempo livre, pois não acredita na existência de um tempo necessariamente livre de coações ou normas. Opta então por tempo disponível, anunciando o lazer como a experiência vivenciada neste tempo. Quanto à atitude, estaria relacionada ao modo como o indivíduo lida com esta experiência (o sentido que dá e obtém da mesma). Assim, demonstra seu entendimento de que o lazer seria a cultura vivenciada (praticada ou fruída) no tempo disponível.

Acreditando que o lazer proporcionaria al go maior do que simplesmente amenizar o sofrimento ou alegrar a vida, critica a organização da sociedade e o fetiche pelo consumo, defendendo o resgate do humano ainda existenteno homem. Exaltando o potencial educativo proporcionado pelo lazer, ora como instrumento de educação (educação pelo lazer), ora como objeto de educação (educação para o lazer), M arcellino revela que não bastaria apenas garantir 0 acesso das pessoas, mas seria necessário produzir e difundir uma cultura popular que, rompendo com as atitudes conformistas, proporcionaria condições a uma participação crítica e criativa, com vistasà instalação da nova ordem social.

Nessa lógica, pelo jogo de expressões como educação e humanização, 0 autor interpreta 0 lazer como a possibilidade de transformar a sociedade. Tendo o indivíduo como epicentro ereconhecendo-o como um ser histórico e social, assinala a necessidade deestimulá-lo em suaimaginação, vontade e poder de escol has. Como um direito, o lazer é exaltado como um instrumento para as pessoas administrarem conflitos, não simplesmente maquiando-0s, mas que, ao fortalecer resistências, impulsionaria utopias. 
Reconhecidamente, estas reflexões deram outros rumos ao campo do lazer no país; entretanto, na atualidade, seu pensamento, além de ser visto por alguns críticos como insuficiente para superar os principais preceitos funcionalistas, ainda aponta uma outra funcionalidade ao lazer. Através de uma mudança frente às necessidades do lazer, Marcellino preocupa-se em humanizar o homem e instalar uma nova ordem social. Para Cavichiolli et al. ${ }^{43}$, o problema é que tal proposição fundamenta-se na crença de que transformações no plano cultural, por menor que fossem, auxiliariam em reflexões que pudessem acarretar também mudanças no plano social.

Mudanças que, na visão de Mascarenhas ${ }^{27}$, dificilmentese concretizam, principalmentepelo fato desta proposição estar pautada no modelo de desenvolvimento comunitário. Um modelo que se preocupa exclusivamente com a mudança de postura frente às necessidades de lazer, sem contribuir com a ruptura das estruturas do mundo do trabalho e das condições de expropriação do poder do povo. Por mais que a participação popular não se restrinja ao estar nas atividades para ocupar o tempo não vinculado às obrigações profissionais, familiares e sociais, suas ações são esvaziadas politicamentee, por isso, revelamse insuficientes na tar efa de instrumentar técnica e politicamente as pessoas para atuarem na meIhoria da sua qualidade de vida e saúde, bem como garantir uma maior participação no controledeste processo. Por consequência, fica aquém dos preceitos da promoção da saúde.

Como se não bastasse, a valorização da atitude frenteàs necessidades do lazer favoreceu sua apropriação pela indústria cultural. Se antes ele era considerado um potencial para a educação e a humanização, agora, diante das profundas transformações na sociedade (econômicas, culturais, políticas, sociais e técnicas) e sua consequenteincorporação pela lógica do lucro, ele passa a ser tratado como mercadoria, o chamado mercolazer ${ }^{27}$. 0 lazer tornou-se um produto da sociedade industrial, ele é ao mesmo tempo um tempo disponível e um objeto de consumo. Ele se vende e se compra. Ele entrou no sistema de consumo que elecontribui para desenvolver na medida em queo tempo disponível para o consumo tende a aumentar. Lazer e consumo estão estreitamente ligados ${ }^{44}$.

E énesta associação/apropriação que a saúde é utilizada como forte apelo de atração, principalmente quando considerado o mercado do fitness (academias, clínicas, hotéis fazenda, spas, atendimentos personalizados, dentre outros). Sob a al egação de queas atividades físicas imuni- zam contra doenças, Solomon ${ }^{45}$ comenta que as pessoas pagam enormes quantias para usufruir seus programas ou serviços. Também revela que, neste investimento, incluem-se roupas, calçados eequipamentos, tidos como imprescindíveis para se obter melhores resultados.

Além de reforçar a valorização dos estilos de vida na promoção da saúde, tendência a qual anteriormente deflagramos seus limites, observa-se no lazer uma verdadeira corrida pelo consumo de atividadesfísicas. Solomon ${ }^{45}$, além de refletir sobreos limites da relação atividade física e saúde, ainda alerta para os perigos deste discurso, apontando lacunas em trabalhos que sustentam a ideia de que a atividade física aumenta a longevidade.

Por conseguinte, acreditamos que a concepção de lazer de M arcellino, na qual se conjugam as categorias tempo e atitude, mesmo que visem conteúdos críticose criativos, éinsuficiente como alternativa ao atual tratamento dado ao lazer na promoção da saúde, pois além dos seus limites em conquistar mudanças estruturais na sociedade, ainda favorece a mercantilização do lazer.

Lazer eeducação popular: possibilidades para uma nova relação lazer e saúde

Parece inevitável queo lazer implique numa relação de consumo. Parece evidente também que este tipo de lazer vinculado ao consumo toma características próprias conformea camada social quedele se ocupa. Em outras palavras, isso quer dizer queo que se consome no tempo de lazer do operário não é o mesmo consumido no tempo de lazer do presidente da mesma fábrica ${ }^{44}$. Enquanto este último vivencia um lazer luxuoso, aos operários resta a vivência de um lazer de segunda mão, marcado pela precariedade e pelo improviso.

A pesar disso, $M$ ascarenhas ${ }^{27}$ acredita queainda é possível a reversão deste quadro; porém, adverte para a necessidade deste pensamento estar conjugado ao projeto de uma outra sociedade, já que as desigual dades que se reproduzem no lazer também estão presentes nas outras esferas da vida, inter-relacionando-se umas às outras.

Nessa tônica, embora as metas sejam planejadas para longo prazo, já que a superação do capitalismo não virá de uma hora para outra, sem vislumbrar um outro lazer como simples abstração teórica, o autor acredita que mudanças mais próximas também devam ser esperadas, como, por exemplo, aquilo que se refere às questões econômicas que incidem sobre as condições de vida da população. Para isto, emba- 
sando-se em princípios éticos-políticos e respeitando as relações do presente e em sintonia com a história, sistematiza uma proposta de atuação que visa à conquista da cidadania mais ativa e participativa.

Tomando como referência a pedagogia crítica de Paulo Freire, fundamenta o que ele chama de lazerania. Pelo diálogo com as classes populares, num dialético teorizar a prática, seu objetivo é a educação. Busca proporcionar meios e condições aos sujeitos que de seu exercício tomam parte para refletirem sobre suas condiç̧ões de vida e sobre a sociedade mais ampla na qual estão inseridos, possibilitando-Ihes não só 0 acesso, mas o entendimento do lazer como manifestação de uma cultura e como possível instrumento de ligação com sua realidade. Deste modo, tem seus propósitos fincados sobrea noção de sujeito social, afastando-se da passividade que cerca a atual condição de consumidor comum à experiência do mercolazer ${ }^{27}$.

Preconizando a noção de direitos e deveres, e incentivando a participação para a tomada de decisões que correspondem à organização deuma dada coletividade, o processo pedagógico toma como ponto de partida o saber anterior dos envolvidos, sem enfatizar a transmissão de conhecimento. Busca ampliar os espaços de interação e negociação entre os envolvidos no lazer e com vistas a determinado problema social, objetivando, pela construção compartilhada do conhecimento, a sua resolução. Além de desmistificar o subjetivismo que cerca a ideia de lazer como fazer o que se quer, também não difunde conceitos nem comportamentos, mas procura problematizar, em uma discussão aberta, o que está incomodando e oprimindo, revelando a liberdade, que deve ser inerente à sua prática, como a consciência da necessidade.

Tidos como parceiros, os envolvidos são convocados a participarem ativamente do redirecionamento do lazer e de outras esferas da vida social. Para Freire ${ }^{46}$, a população não deve apenas ser guiada ou empurrada por seu líder até aquilo com o que sonham, mas deve participar dos debates em torno do projeto de um mundo diferente. N esse sentido, a partici pação aqui é vista como o resultado de um processo de formação humana, que visa estimular a organização popular para se impor e autodeterminar, a iniciar pelas atividades e pelo tempo de lazer.

Dessa forma, com base em $\mathrm{Demo}^{33}$, compreendemos a lazerania como uma política social organizada pela sociedade civil e que se contrapõe, não simplesmente ao Estado, mas especificamente contra a transferência de seu controle e regulação para o mercado. Com sua intervenção, espera-se que mudanças na estrutura política acarretem mudanças também na estrutura econômica. Isso porquea mudança política passa necessariamente pela participação da população nas suas decisões.

Nessa lógica, vemos na lazerania uma possibilidade concreta para o lazer ser situado como um "verdadeiro" aliado para a promoção da saúde, pois seu propósito éo diálogo com a população, a fim de instrumentá-la técnica e politicamente para o enfrentamento de situações adversas. Assim, acaba assemelhando-se em muito com as práticas de educação popular em saúde que, para Vasconcellos ${ }^{47}$,é 0 jeito brasileiro de se promover saúde.

Tanto a lazerania como as práticas de educação popular em saúde priorizam a relação com movimentos sociais, visando à formação de redes entre os mesmos. A escolha por estes grupos deve-se ao fato deles representarem os interesses dos setores mais subalternos da sociedade, e que normalmente são desprovidos de voz em diálogos e negociações. Embora quase sempre partam da busca de soluções para problemas específicos e localizados, o fazem a partir da perspectiva dequea atuação na mi crocapilaridadeda vida social é uma estratégia de desfazer os mecanismos de cumplicidade, apoio ealiança, os micropoderes, que sustentam as grandes estruturas de domi nação política e econômica da sociedade ${ }^{47}$.

Portanto, engajam-se no objetivo do incremento de consciência política da população para superação da subordinação, exclusão e opressão que marcam a vida na sociedade contemporânea. E, nesta tarefa, o fenômeno esportivo pode ser um potente instrumento. Porém, para isto, elenão deveser ensinado como uma mera cópia do esporte derendimento, ou sua incessantebusca pela formação de atletas e desenvolvimento da aptidão física.

Como elemento da cultura corporal, o esporte pode tanto possibilitar a reprodução das relações excludentes e preconceituosas enraizadas na cultura, como, ao ser problematizado, possibilitar a superação dessas práticas numa reflexão crítica da realidade ${ }^{48}$. Com este raciocínio e apoiados em Paulo Freire, Capela et al..$^{49}$ refletem o esporte em prol da emancipação e como elemento fundamental da defesa da vida humana, assinalando que quando seu ensino é pensado a partir de transformações didáticas que incorporam novas concepções antropológica, filosófica e científica, é possível superar o pensamento hegemônico, um tanto quanto elitista e machista, eque privilegia a 
simples reprodução das técnicas e regras do esporte de rendimento nos moldes olímpicos.

Pela problematização das suas atuais formas e manifestações (como jogo, técnica de corpo, espetáculo, mercadoria, etc.), criam-secondições facilitadoras à conscientização dos envolvidos acerca da importância da participação de todos para se construir uma sociedade fundada na solidariedade ecom menos injustiças sociais. N este sentido, o futebol desponta como uma estratégica ferramenta pedagógica. Para DaM atta, citado por $\mathrm{Vaz}^{50}$, este esporte proporciona momentos democráticos e críticos, que ao serem associados a outras esferas da vida humana, podem contribuir para o exercício da cidadania. N esse prisma, por exemplo, aponta que, da mesma forma com que os torcedores pressionam jogadores e treinadores por causa de seus erros, a população também deveria portar-se frente aos governantes e outros poderosos.

Uma possibilidade para se pensar ecolocar isso em prática seria uma escolinha de futebol desenvolvida por temas geradores. Os temas geradores constituem-se num processo de busca, de conhecimento, por isto tudo, decriação, exigedeseus sujeitos que vão descobrindo, no encadeamento dos temas significativos, a interpenetração dos problema ${ }^{51}$. Para ilustrar, apresentamos os eixos de atuação propostos por Honrich et al..$^{52}$ para um trabalho de formação de jogadores nas categorias de base:

- Movimento corporal: sob o entendimento dequeo movimento corporal é muito mais complexo do que revelam as análises científicas acerca de gestos estereotipados, ignorando a existência de um ser social se movimentando, seria necessário considerar o mundo vivido das crianças, que érico em vivências corporais, tais como as advindas pelas brincadeiras na rua, na ladeira, soltando pipa, pulando valas, etc.;

- Obtenção da maioridade sócio-política: a espetacularização do futebol tem transformado o jogador de futebol num produto rentável que, sem senso crítico e reflexivo, permite a exploração de sua força de trabalho. Esta exploração, por conta da legislação (Lei Zico, Lei Pelé, etc.), tem ocorrido cada vez mais cedo e perdura até o momento em que há retorno financeiro com a mesma. Como superação, propõe-se que a formação de novos jogadores vise a sua resistência no que tange a sua dominação, como, por exemplo, com o conhecimento de seus direitos, nos quais seincluem as condições necessárias para se praticar o esporte com qualidade e segurança, afinal, o jogador de futebol deve ser visto como um trabalhador do esporte;
- Interação social: 0 intenso processo de exclusão observado na sociedade contemporânea leva milhares de crianças a sonharem em melhorar suas condições de vida através do futebol. 0 problema é que por poucos assim conseguirem, a competição entre uns e outros é crescente, intensificando-se ainda mais o individual ismo. Nesse sentido, recomendam-se as práticas que possam favorecer (resgatar) o sentido da coletividade presente no futebol;

- Além da técnica: quando uma criança ingressa numa escolinha de futebol, é indiscutível que o seu desejo é aprender a jogar esse esporte. N essa direção, acima da instrumentação técnica, deve-se respeitar o interesse das crianças, o mundo/cultura em quevivem, valorizando sua iniciativa, imagi nação e reflexão.

Sendo assim, compreendemos que o ensino/ aprendizagem de técnicas, regras e táticas do futebol não deve ser a finalidade da escolinha, mas, por exemplo, um meio capaz deinstigar a solidariedade entre os envolvidos, bem como a descoberta progressiva de que, como cidadãos, eles podem e devem reivindicar o seu direito a um espaço público e de qualidade para vivenciar o futebol e, consequentemente, o seu lazer. Ao iniciar pela conquista de espaços de qualidade para - lazer, também se pode pensar em ações maiores que visam à conquista da sociedade e saúde que queremos.

\section{Conclusão}

Iniciamos este trabal ho com o objetivo de apresentar concepções críticas e alternativas do lazer em sua relação com a saúde, uma vez que na educação física brasileira existem proposições concretas para superar a lógica da simples ocupação ativa do corpo no tempo de lazer, mas que ainda permanecem desconhecidas pela Saúde Pública e Saúde Coletiva brasileiras.

N este sentido, partindo da compreensão da promoção da saúde como o incremento da consciência política da população para sua organização em direção da conquista de ambientes favoráveis à saúde, uma revisão bibliográfica sobre o desenvolvimento do campo do lazer revelou que as concepções dos autores mais referenciados neste campo - Dumazedier e M arcellino - são insuficientes nesta complexa tarefa. 0 primeiro, porque tem sua concepção sustentada em observações e enquetes acerca de como a população ocupa o tempo não vinculado às obrigações profissionais, familiares e sociais. Assim, por se tra- 
tar de meras atividades de passatempo e que, muitas vezes, servem de compensação às insatisfações da vida social, sem cogitar a necessidade de mudanças estruturais na sociedade, revelam a influência do pensamento funcionalista, o qual indiscutivelmente não contribui para o enfrentamento do quadro de pobreza e exclusão social que se intensifica na sociedade.

A concepção de M arcellino, por sua vez, mesmo que tenha sido propugnada como alternativa desuperação as ideias de Dumazedier, também se revela limitada para a responsabilidade de promover a saúde. Isto porque, ao estar pautada no modelo de desenvolvimento comunitário, acre dita-se que a simples mudança de postura frente às necessidades de lazer já seria suficiente para transformar a sociedade global. 0 problema, no entanto, éque esta crença, esvaziada politicamente, éincapaz de romper com as estruturas políticas e econômicas vigentes, já quenão se preocupa com a alteração do mundo do trabalho, nem com a expropriação do poder do povo. Como se não bastasse, ao se valorizar a categoria atitude no lazer, favoreceu a apropriação deste tempo pela indústria cultural e sua consequente mercantilização. Assim, nesta lógica, a saúde seria reflexo direto do consumo de produtos e serviços, algo totalmente desalinhado aos pressupostos do movimento da promoção da saúde.

Ao constatar os limites destas concepções, e buscar alternativas às mesmas, encontramos na pedagogia crítica do lazer (lazerania) uma possibilidade concreta para assim proceder. Trata-se de uma concepção que tem como consigna básica a preocupação de propiciar um lazer emancipatório, duradouro e, portanto, contrário ao lazer de improviso e esporádico.

Se promover saúde significa desafiar interesses poderosos, principal mente aqueles preocupados com a manutenção do quadro de dominação dos mais pobres, a consolidação do lazer para a saúde deve estar direcionada para a emancipação humana. Como um processo de aquisição da consciência política da população, através do diálogo com a mesma, acreditamos que a problematização do ensino do fenômeno esportivo, especialmente o futebol, possa orientar uma ação pedagógica voltada para a apuração do sentir, pensar e agir da população para a construção de uma sociedade fundada na solidariedade, garantindo que a participação popular não se resuma ao simples engajamento em atividades sistemáticas e reprodutoras de gestos formatados e al ienados, supostamente servindo para prevenir doenças ou pensadas no combate ao sedentarismo.
É fato que o lazer somente estará alinhado à promoção da saúde caso as demais esferas da vida humana sejam consideradas, afinal, a própria história do lazer revela que o mesmo decorreu da insatisfação dos trabalhadores para com suas condições devida degradantes. Então, épreciso recuperar a historicidade das lutas que 0 impulsionaram. É urgente que propiciemos momentos para que as pessoas usufruam toda a potencialidade do seu tempo de lazer, em especial, para lutar pela prática de liberdade eexercício da cidadania.

Assim, em linhas gerais, épelo resgateda consciência social que se pode impulsionar uma organização solidária capaz de romper com as estruturas materiais, políticas e culturais, que são as grandes responsáveis pela concentração do poder na sociedade contemporânea e, portanto, pela privação de um viver coletivo e salutar. Nessa lógica, a luta pela consciência social visa unificar as utopias construídas para libertação do ser humano da exploração econômica, da dominação política e cultural, ou seja, o lazer que se propõe é em favor da emancipação humana e em resposta a todas as formas de exploração, por vezes travestidas de atividades lúdicas oferecidas com ares de generosidade.

\section{Colaboradores}

M S Bacheladenski participou na condição de autor da dissertação de mestrado em educação física (UFSC) que deu origem ao presente texto autoral. E M atiello Júnior participou, como orientador, do processo de elaboração da dissertação, a partir da qual conjuntamente foi desenvolvido o presente texto. 


\section{Referências}

1. M inayo M CS. O desafio do conhecimento: pesquisa qualitativa em saúde. 8a ed. São Paulo: Hucitec; 2004.

2. Peres FF, Bodstein R, Ramos CL, Marcondes WB Lazer, esporte e cultura na agenda local: a experiência de promoção da saúde em M anguinhos. Cien Saude Colet 2005; 10(3):757-769.

3. Aerts D, Alves GG, Savia MW, Abegg C. Promoção de saúde: a convergência entre as propostas da vigilância da saúde e da escola cidadã. Cad Saude Publica 2004; 20(4):1020-1028.

4. Alves RB. Vigilância em saúde do trabalhador e promoção da saúde: aproximações possíveis e desafios. Cad Saude Publica 2003; 19(1):319-322.

5. Pedrosa JIS. Perspectivas na avaliação em promoção da saúde: uma abordagem institucional. Cien Saude Colet 2004; 9(3):617-626.

6. Souza EM, Grundy E. Promoção da saúde, epidemiologia social e capital social: inter-relações e perspectivas para a saúde pública. Cad Saude Publica 2004; 20(5):1354-1360.

7. Teixeira CF. Promoção e vigilância da saúde no contexto da regionalização da assistência à saúde no SU S. Cad Saude Publica 2002; 18(Suplemento): $153-162$

8. Teixeira JBA, Nogueira MS. Câncer gástrico: fatores de risco em clientes atendidos nos serviços de atenção terciária em um município do interior paulista. Rev Latino-am Enfermagem 2003; 11(1):43-48.

9. Zancan L, Adesse L. Informe sobre a cooperação Brasil-Canadá em promoção da saúde. Cien Saude Colet 2004; 9(3):739-744.

10. M inayo M CS, Hartz ZM A, Buss PM. Qualidade de vida e saúde: um debate necessário. Cien Saude Colet 2000; 5(1):7-18

11. Queiroz CMB, Sá ENC, Assis M MA. Qualidade de vida e políticas públicas no município de Feira de Santana. Cien Saude Colet 2004; 9(2):411-421.

12. Adriano JR, Werneck GAF, Santos MA, Souza, RC A construção de cidades saudáveis: uma estratégia viável para a melhoria da qualidade de vida? Cien Saude Colet 2000; 5(1):53-62.

13. Assis SG, Avanci JQ, Silva CM FP, Malaquias JV, Santos NC, Oliveira RVC. A representação social do ser adolescente: um passo decisivo na promoção da saúde. Cien Saude Colet 2003; 8(3):669-679.

14. Becker D, Edmundo K, Nunes NR, Bonatto D, Souza R. Empowerment e avaliação participativa em um programa de desenvolvimento local e promoção da saúde. Cien Saude Colet 2004; 9(3):655-667.

15. Camargo RAA, Bueno SM V. Lazer, a vida além do trabalho para uma equipe de futebol entre trabaIhadores de hospital. Rev Latino-am Enfermagem 2003; 11(4):490-498.

16. Cardoso CP, Cocco MIM. Projeto de vida de um grupo de adolescentes à luz de Paulo Freire. Rev Latino-am Enfermagem 2003; 11(6):778-785.

17. Carvalho CMRG, Fonseca CCC, Pedrosa JI. Educação para a saúde em osteoporose com idosos de um programa universitário: repercussões. Cad Saude Publica 2004; 20(3):719-726.
18. M elo EM, Faria HP, M elo MAM, Chaves AB, Machado GP. Projeto Meninos do Rio: mundo da vida, adolescência e riscos de saúde. Cad Saude Publica 2005; 21(1):39-48.

19. M oysés SJ, Moysés ST, Krempel MC. Avaliando o processo de construção de políticas públicas de promoção de saúde: a experiência de Curitiba. Cien Saude Colet 2004; 9(3):627-641.

20. Muza GM , Costa M P. Elementos para a elaboração de um projeto de promoção à saúde e desenvolvimento dos adolescentes: 0 olhar dos adolescentes. Cad Saude Publica 2002; 18(1):321-328.

21. Palha PF, Lima GM, Mendes IJM. Programa de integração comunitária: em busca de novas estratégias e novos sentidos à vida. Rev Latino-am Enfermagem 2000; 8(2):5-10.

22. Sperandio AMG, Correa CRS, Serrano MM, Rangel HA. Caminho para a construção coletiva de ambientes saudáveis: São Paulo, Brasil. Cien Saude Colet 2004; 9(3):643-654.

23. Veras RP, Caldas CP. Promovendo a saúde e a cidadania do idoso: o movimento das universidades da terceira idade. Cien Saude Colet 2004; 9(2):423-432.

24. Awofeso N. What's new about the "N ew Public $\mathrm{He}$ alth"? Am J Public Health 2004; 94(5):705-709.

25. M atiello Júnior $E$, Gonçalves $A$. Entre a bricolagem e o personal training, ou... a relação atividade física e saúde nos limites da ética. In: Anais do XII Congresso Brasileiro de Ciências do Esporte; 2001; Caxambu. [CD-ROM]

26. Soares C. Educação física: raízes européias e Brasil. Campinas: Autores Associados; 1994.

27. M ascarenhas F. Entre o ócio e o negócio: teses acerca da anatomia do lazer [tese]. Campinas (SP): Faculdade de Educação Física: Universidade Estadual de Campinas; 2005.

28. Buss PM. Promoção da saúde e qualidade de vida. Cien Saude Colet 2000; 5(1):163-177.

29. Lefevre F, Lefevre AM C. Promoção de Saúde: a negação da negação. Rio de Janeiro: Vieira \& Lent; 2004.

30. Buss PM. Uma introdução ao conceito de promoção da saúde. In: Czeresnia D, Freitas CM, organizadores. Promoção da Saúde: conceitos, reflexões, tendências. Rio de Janeiro: Fiocruz; 2003. p. 39-53.

31. Brasil. M inistério da Saúde. Promoção da Saúde: Declaração de Alma-Ata, Carta de Ottawa, Declaração de Adelaide, Declaração de Sundsvall, Declaração de Santafé de Bogotá, Declaração de Jacarta, Rede de M egapaíses e Declaração do M éxico. 2a ed. Brasília: M inistério da Saúde; 2001.

32. Andrade GRB, Vaitsman J. Apoio social e redes: conectando solidariedade e saúde. Cien Saude Colet 2002; 7(4):925-934

33. Demo P. Participação é conquista. 3a ed. São Paulo: Cortez; 1996.

34. Dumazedier J. Lazer e cultura popular. São Paulo: Perspectiva; 1976.

35. Marcellino NC. Lazer e educação. 4a ed. Campinas: Papirus; 1998.

36. M elo VA, Alves Júnior ED. Introdução ao lazer. Barueri: Manole; 2003. 
37. Frigotto G. Os delírios da razão: crise do capital e metamorfose conceitual no campo educacional. In: Gentili P, organizador. Pedagogia da exclusão: crítica ao neoliberalismo em educação. Petrópolis: Vozes; 1995. p. 77-108.

38. Padilha V. Tempo livre e capitalismo: um par imperfeito. Campinas: Alínea; 2000.

39. Barata RB. Epidemiologia social. Rev. bras. epidemiol. 2005; 8(1):7-17.

40. M inayo MCS. Mudança: conceito-chave para intervenções sociais e para avaliação de programas. In: M inayo MCS, Assis SG, Souza ER, organizadores. Avaliação por triangulação de métodos: abordagem de programas sociais. Rio de Janeiro: Fiocruz; 2005. p. 53-70.

41. Santos M. O espaço do cidadão. 4a ed. São Paulo: Nobel; 1998.

42. Freire P. Educação e mudança. 14a ed. Rio de Janeiro: Paz e Terra; 1988.

43. Cavichiolli F, Cheluchiniak AB, Augusto VN. A influência dos preceitos funcionalistas nos autores mais populares da área do lazer. In: Anais do XIV Congresso Brasileiro de Ciências do Esporte e I Congresso Internacional de Ciências do Esporte; 2005; Porto Alegre. [CD-ROM]

44. Marin EC, Padilha V. Lazer e consumo no espaço urbano. In: Almeida CPC, DaCosta LP, organizadores. M eio ambiente, esporte, lazer e turismo: estudos e pesquisas no Brasil 1967 - 2007. Rio de Janeiro: UGF; 2007. p. 289-298.

45. Solomon HA. O mito do exercício. São Paulo: Summus; 1991.

46. Freire P. Pedagogia da indignação: cartas pedagógicas e outros escritos. São Paulo: Unesp; 2000.

47. Vasconcellos EM. Educação popular: de uma prática alternativa a uma estratégia de gestão participativa das políticas de saúde. Physis 2004; 14(1):67-83.

48. Grando BS. Corpo e educação: as relações interculturais nas práticas corporais Bororo em M eruri - MT [dissertação]. Florianópolis (SC): Universidade Federal de Santa Catarina; 2004.

49. Capela PRC, Matiello Júnior E. El deporte y la liberación humana. In: Breilh J, organizador. Informe alternativo sobre la salud en América Latina. Quito: Somos Punto y Línea; 2005. p. 270-275.

50. Vaz AF. DaMatta: o futebol como drama e mitologia. In: Proni MW, Lucena RF. Esporte: História e Sociedade. Campinas: Autores Associados; 2002. p. 139-164.

51. Freire P. Pedagogia do oprimido. $44^{a}$ ed. Rio de Janeiro: Paz e Terra; 2005.

52. Honrich CA, Souza JCC. Para além da questão da técnica do ensinar/aprender futebol: outras possibilidades. In: Kunz E, organizador. Didática da educação física 3: futebol. Ijuí: Unijuí; 2003. p. 41-87.

Artigo apresentado em 03/01/2007

Aprovado em 17/12/2007

Versão final apresentada em 12/01/2008 